\title{
AMAZON'S STEP TOWARDS CLEAN ENERGY AND ITS IMPORTANT ON THE USA
}

\author{
${ }^{1}$ Fitri Silaban, ${ }^{2}$ Puan Maharani P.A, ${ }^{3}$ Sartika Laurenvia Yohana, ${ }^{4}$ Veryzal \\ ${ }^{1234}$ International Relations, President University, Cikarang, Indonesia \\ ${ }^{1}$ fitri.silaban@student.president.ac.id, ${ }^{2}$ puan.admoko@student.president.ac.id, \\ ${ }^{3}$ sartika.yohana@student.president.ac.id, ${ }^{4}$ veryzal@student.president.ac.id
}

\begin{abstract}
Amazon is an American company that is based in Seattle. This company deals in e-commerce, it's the largest internet-based store and is owned by Jeff Bezos. The company was founded on July 5, 1994. With Amazon committed to a climate pledge, this means amazon has the responsibility to make a change towards the environment and the world Amazon purchases renewable energy outside of the current grid mix to promote the production and creation of new renewable energy. These sources were diverse in order to collect enough information: books, journals, and websites were all included in the creation of this text. Since we used to be able to comprehend sentences and perceptions, we use qualitative research analyst approaches to collect data. Renewable energy comes from naturally restoring yet flow-limited sources. Renewable resources are basically limitless in terms of duration but have a finite quantity of energy per amount of time. Amazon has a huge impact on the economy in the US. With the many investments that Amazon has made for the development of its own employees and unfortunate children. According to the North Carolina sustainable energy association clean energy includes both renewable energy and energy saved through energy efficiency measures. And with Amazon and Tesla being US-based companies this will make the U.S seen as a country with advanced technology and also become advanced and foremost in terms of politics of energy.
\end{abstract}

Keywords: Amazon, clean energy, Jeff Bezos, renewable energy

DOI: 10.33541/sp.v22i2.3484

Sociae Polites: Majalah IImiah Sosial Politik

Faculty of Social and Political Science, Universitas Kristen Indonesia

ISSN 1410-3745 print/ ISSN 2620-4975 online

Volume 22, Number 2 (July-December 2021)

Pages 92-100 


\section{Introduction}

Amazon is an American company that is based in Seattle. This company deals in e-commerce, it's the largest internet-based store and is owned by Jeff Bezos. The company was founded on July 5, 1994. With Amazon committed to a climate pledge, this means amazon has the responsibility to make a change towards the environment and the world Amazon purchases renewable energy outside of the current grid mix to encourage the production and development of new renewable energy sources. Amazon works with energy companies all over the world to develop innovative solar solutions to help us fulfill our demands. Long-term contracts, such as power purchase agreements with huge wind and solar projects that are connected to the same energy grids as our own, permit many of these projects. Amazon also striking a deal to buy 380 megawatts (MW) of wind energy from Hollandse Kust Noord, a wind farm off the coast of Netherlands that's being developed by The Crosswind, a consortium between oil major Royal Dutch Shell, Eneco, a Netherlands-based energy company owned by Japan's Mitsubishi (Mathis, 2020).

A windmill is a structure that converts wind energy into motion energy by utilizing fan blades known as sails or blades, primarily for milling grain, although the name is also applied to wind pumps, wind turbines, and other applications. The phrase "wind engine" is commonly used to describe such machines. Windmills were utilized in the late medieval and early modern periods; the horizontal or panemone windmill first arose in greater Iran in the 9th century, and the vertical windmill first appeared in northwestern Europe in the twelfth century. Thought to be an icon of dutch culture, there are or so 1,000 windmills within the Netherlands these days.

Clean energy could be defined as energy generated using non-polluting technologies that do not emit greenhouse gases or other pollutants (Shinn, 2018). Renewable energy sources such as solar and air currents can be used to generate clean energy. It's important to understand that the phrases renewable energy and clean energy are not synonymous. Energy power, for example, is a renewable energy source. However, some of the methods for processing it will have an adverse effect on the environment. Unpolluted energy has the advantage of reducing our dependence on fossil fuels while also having the potential to ameliorate global climate change. Coal and alternative fossil fuels account for more than a third of all emissions in the United States.

One of the reasons why Amazon is now playing in the field of clean energy is that Amazon as a company has a pledge within their company as an organization that will be one of the agents of change in terms of sustainability and also ahead in the clean energy field. The reason for this is that Amazon wanted to Implement decarbonization policies in accordance with the Paris Agreement by implementing industry changes and technologies, such as productivity upgrades, renewable energy, content reductions, and other carbon emission reduction strategies (Amazon, 2019).

\subsection{Research Question}

To be more clear on what this paper is talking about, in this part of the paper we are attaching the points of what is our research question. This research point will then be the basis of our literature review.

- What is clean energy or renewable energy?

- What is Amazon's purpose in stepping into the clean energy sector?

- How is Amazon stepping into the clean energy sector impacting the USA? 


\subsection{Purpose and Objective}

The Objective of the research is to assess the impact on the multinational company Amazon, founded by Jeff Bezos, and its clean energy and renewable energy program in the United States of America. Quantitative approaches were used to conduct a thorough and in-depth investigation of a certain issue or concern. An in-depth examination of data allows for the emergence of new ideas, concepts, and understandings. The research's main purpose is to uncover new possibilities. It's a requirement for understanding the subject.

\section{Literature Review}

\subsection{Renewable Energy; An Overview}

Renewable energy comes from naturally renewing but flow-limited sources; renewable resources are nearly limitless in length but have a finite amount of energy per unit of time. This assures that this energy can be replenished continuously as long as there is an energy supply to refresh it with. Using renewable energy is safer for the world. Because renewable energy technologies contain few impurities, they are frequently referred to as "clean" or "green" technology. Burning fossil fuels, on the other hand, puts greenhouse gases into the atmosphere, trapping heat from the sun and contributing to global warming. According to climate scientists, the earth's average temperature has risen during the previous century. Sea levels will increase as a result of this pattern, and floods, heatwaves, droughts, and other extreme weather will become more common. Renewable energies would assist us in achieving energy efficiency and freedom (Tromly, 2001).

Solar systems provide heat, light, and energy by directly tapping into the sun's inexhaustible power. Solar energy is a renewable resource that can be transformed into electricity in two different ways. Photovoltaic material generates an electrical potential when exposed to light. Electrons that are negatively charged are released from their atoms, allowing them to readily flow through the material and generate energy. This energy is temporarily held in an accumulator or battery before being sent into an inverter circuit, which converts DC power into the 220-240 volt AC (alternating current) required to power various electrical gadgets in households (Nathan David, Abioye Ayodeji Opeyemi, 2013).

Variations in air temperature and pressure trigger winds. The variations are caused by the uneven heat distribution from the sun and differences within the heat capacity of the ocean and the land surfaces. Warmer air has a tendency to pass over warmer, heavier air. The Earth's rotation typically greatly modifies wind produced in this manner. Since 1990, wind energy has continuously risen over $25 \%$ each year, making it the world's fastest-growing source of energy. It's a development fuelled in part by major advances in wind power generation. The amount of solar energy intercepted by the earth exceeds the amount of fossil fuels utilized by the world every minute. The energy contained in the winds that cross over the United States every year, for example, could generate about 16 billion GJ of electricity. In comparison to human needs, the entire planet's energy storages and flows are enormous.

On September 9th, 2019, an Amazon employees group wrote a blog post 
claiming that "Amazon contributes directly to climate change" by relying heavily on fossil fuels in their operations and polluting communities with their fossil-fuel infrastructure. The fact that Amazon Web Services includes oil and gas companies as clients irritate the employees as well. The employees' community wants Amazon Web Services to stop developing custom applications for the production and the exploration of oil and gas. They also want Amazon to stop supporting politicians who postpone climate change action (Amazon Employees for Climate Justice, 2019).

\subsection{Amazon's Impact on United States' Growth}

In the last 25 years, Amazon is one of the most successful small companies and has grown to become the second-largest company in the US. With that success, Amazon had an impact on the US economy. Amazon has invested heavily in the US since 2010. The company has invested in corporate offices, cloud infrastructure, wind and solar farms, environmentally friendly machines and equipment, and their team's compensation, for more than $\$ 350$ billion dollars. Amazon invests in the development of technology in our headquarters, head office in Arlington, Virginia, and 16 technology centers throughout the US. With this rapid investment, it is estimated that Amazon has contributed as much as \$ 315 billion dollars to US GDP since 2010 (Amazon, 2020).

Amazon also creates a lot of jobs for the U.S. Amazon has already invested 2.7 million workers in the US (800,000 US employees from 40 major countries and 250 counties). Not only that, but Amazon also helps and supports Small and Medium-sized Businesses (SMBs) by selling products online, and as a result, there are 1.1 million workers in the community in the US because of the growing sales on Amazon. In fact, SMBs from 50 states selling via Amazon more than doubled their hiring growth rate of 25-50\% compared to those which didn't, according to IDC. Amazon also sets a minimum wage of $\$ 15$ for its employees with the addition of receiving quality benefits and access to learning to various programs with the aim that employees can learn new skills, as part of upskilling 2025. With this Amazon commitment to providing funds of $\$ 700$ million to support all employees so they can upgrade their skills.

With the data above, Amazon has a huge impact on the economy in the US. With the many investments that Amazon has made for the development of its own employees and unfortunate children. The company pays a high amount of taxes. And many companies donate for the welfare of the community. And Amazon can say that it generalizes the states it is in the US because they take on employees from 40 states. With these donations and investments, according to the author, Amazon is like giving a little relief to the government looking for solutions to the challenges of homelessness. Where the government must also find solutions to overcome the quality of education for unfortunate children and overcome homelessness.

\section{Research Methods}

Renewable energy is derived from naturally replenishing but flow-limited sources; renewable resources are virtually unlimited in terms of length but contain a finite amount of energy per unit of time. The energy contained in the winds that blow over the United States every year, for example, could generate about 16 billion GJ of 
electricity. Amazon paid more than $\$ 1$ billion in federal tax fees in 2019, more than $\$$ 2.4 billion in additional federal tax payments, and more than $\$ 1.6$ billion in state and local taxes in 2019.

Our research methods are designed to provide some comprehensive information about our subject, so we have specific issues. This project was accomplished entirely through bibliographic analysis, which included both primary and secondary sources. These sources were diverse in order to collect enough information: books, journals, and websites were all included in the creation of this text. The bulk of the information came from journals and papers. Since we used to be able to comprehend sentences, feelings, and perceptions, we use qualitative analyst approaches to collect data. Open-ended survey and interview questions literature reviews other states Based Services are all good places to start with qualitative research. In this paper, therefore we use the Qualitative method, research that contains a systematic factual, and accurate description of the fact and properties of certain objects. For researchers familiar with quantitative ways that aim to measure one thing (such as the proportion of individuals with a specific sickness in a community, or the amount of households owning a bed net), the aims and methods of qualitative research will appear inaccurate.

\section{Results and Discussions}

By joining the climate pledge and working by the conduct that has been stated in the pledge Amazon is now more conscious about the greenhouse gas emissions that its company is harboring something. As a result, the corporation is required to take rigorous measurements and report on greenhouse gas emissions on a regular basis. Also, through corporate change and innovation, adopting decarbonization initiatives in line with the Paris Agreement, such as efficiency improvements, renewable energy, material reductions, and other carbon emission reduction strategies. With the outcomes of a corporation that is more concerned about the future environment, as well as a model for many other businesses and their clients and consumers.

Clean energy has become a huge success story in the United States. Jobs are created when businesses invest in renewable energy: employment in the sector has increased since 2015, according to Clean Jobs America 2020. Prior to COVID, over 3.3 million workers were employed in these cleantech industries. However, the pandemic has whittled away at those possibilities. Despite the pandemic and the economic downturn, 2020 was a turbulent year, but Businesses are likely to acquire more renewable energy as the country gets its arms around the coronavirus and improves its economic outlook in 2020, despite the fact that it was a tumultuous year. They will be motivated, though, because a new pioneer is attempting to set the country on an irreversible route to net-zero carbon emissions by the middle of the century (K.Silverstein, 2021).

This movement that Amazon started will also open up the possibility of the society or the community to follow this initiative to start using the alternative of clean energy thus using more minimal fossil-based energy. Which then will reduce the bad for the environment waste to affect our environment. But even so, starting a new lifestyle is proven to be hard and complicated and that is why our group will include the discussion of the pros and cons of this clean energy.

Pros 
- A breakthrough and many environment-friendly energy solutions.

- Cutting carbon emissions.

- Contributing to a fight against climate change.

- Save on packaging costs.

- As one of the leading companies that can bring a change and big contribution to the state.

Cons

- The windmill yard could be an expensive solution.

- An alternative that is relatively new in the USA.

- It requires large initial capital to procure and make sure the windmill is of top-notch quality.

- There is a possibility that clean energy is unreliable.

- Reducing packaging's stuff might affect the goods' security.

Then how will this movement affect the consumers of Amazon and also the people of the USA?

In September 2020 Amazon unveiled new solutions for users to lower their devices' energy consumption, as well as gadgets made with more recycled materials and packaged in more environmentally friendly ways. Amazon is concerned about the state of our planet's health. They co-founded the Climate Pledge last year, a pledge to make our company carbon neutral by 2040 . They've made good progress since then and aren't slowing down. Across all aspects of our business, including devices and services, Amazon continues to develop more sustainable solutions. In 2020, Amazon became the first consumer electronics company to pledge to address its products' consumption processes through green energy initiatives. They're currently building new wind and solar panels in order to create enough renewable energy to power each Echo unit. The first Amazon Devices wind and solar farms were erected in the United States, with the ambitious goal of continuing to create new renewable energy projects until they cover all Amazon device energy consumption (R. Praetorius, 2020).

Furthermore, they are working towards making their devices more energyefficient, as this is good for the environment as well as their customers. As a result, all new wall-powered Echo and Fire TV devices now have a Low Power Mode feature that reduces their lifetime energy use by requiring less power during idleness. They'll also be issuing free over-the-air upgrades that will allow users to use Low Power Mode on additional devices they already own.. They're also launching "Compact by Design," a new certification for goods that minimize carbon emissions by improving production and packaging. Amazon has launched Climate Pledge Friendly, a new initiative aimed at making it easier for consumers to find and purchase more environmentally friendly goods. Customers can also see the Climate Pledge Friendly mark while shopping for over 25,000 goods, indicating that the products have one or more of 19 different environmental certifications that help protect the natural environment, such as reducing the carbon footprint of consumer shipments (Amazon, 2020). Amazon also put a surcharge on retailers who meet such packaging quotas in order to reduce packaging waste and its own handling costs (J.T Peltz, 2019).

\section{Conclusions and Recommendations}

Amazon works with energy companies all over the world to develop innovative 
solar solutions to help us fulfill our demands. Renewable energy sources such as solar and air currents can be used to generate clean energy. Energy power, for example, is a renewable energy source, but some methods of handling it have a negative impact on the environment. Renewable energy is derived from naturally replenishing but flowlimited sources; renewable resources are virtually unlimited in terms of length but contain a finite amount of energy per unit of time. It is safer for the world to use renewable energy. Amazon has committed to setting a minimum wage with the addition of receiving quality benefits and access to learning to various programs for their employees, adding specific funds for them, with the aim that employees can upgrade and learn new skills, as part of upskilling 2025. The way Amazon started to contribute to the fight against climate change is a shining example that a corporation can also contribute or give back to the community. And it is also interesting to see how Amazon can mix business, technology, and also clean energy is for sure a brilliant way to make sure that its consumers and clients are more aware of how severe a climate change impact will be on our environment. If a company as big as Amazon manages to demonstrate its commitment to this, then it is possible to become an influence for other big corporations or e-commerce companies all over the world to follow in Amazon's footsteps. And of course, the more amazing benefit of Amazon starting to join the clean energy fields with the help of the big name of Jeff Bezos and the publicity, it could carry and means a bigger chance to affect people and contribute to the economy of the United States. 


\section{Bibliography}

\section{Books}

Hagen, K. D. Introduction to renewable energy for engineers. Pearson, 2015.

\section{Websites}

"5 Advantages of Solar Power." Sunrun. Last modified September 26, 2019. https://www.sunrun.com/go-solar-center/solar-articles/5-advantages-solarpower.

"Amazon Buys Solar, Wind Power to Speed Shift to a Renewable AWS Cloud." Data Center Frontier. Last modified December 10, 2020. https://datacenterfrontier.com/amazon-buys-green-power-to-speed-shift-torenewable-aws-cloud/.

Amazon Employees for Climate Justice. "Amazon Employees Are Joining the Global Climate Walkout, 9/20." Medium. Last modified September 20, $2019 . \quad$ https://amazonemployees4climatejustice.medium.com/amazonemployees-are-joining-the-global-climate-walkout-9-20-9bfa4cbb1ce3.

"Amazon.com Inc." Bloomberg.com. Accessed May 10, 2021. https://www.bloomberg.com/profile/company/AMZN:US.

Amazon. "Amazon Launches "Climate Pledge Friendly" Program." About Amazon. Last modified November 2020. https://www.aboutamazon.com/news/sustainability/amazon-launchesclimate-pledge-friendly-program.

Amazon. "Amazon Launches a \$2 Billion Climate Pledge Fund." About Amazon. $\begin{array}{lll}\text { Last } \quad \text { modified } & \text { November }\end{array}$ https://www.aboutamazon.com/news/sustainability/amazon-launches-a-2billion-climate-pledge-fund.

Amazon. "Renewable Energy." Sustainability - US. Accessed May 10, 2021. https://sustainability.aboutamazon.com/environment/sustainableoperations/renewable-energy?energyType=true.

Amazon. "The Climate Pledge Celebrates Surpassing 100 Signatories." About Amazon. Last modified April 23, 2021. https://www.aboutamazon.com/news/sustainability/the-climate-pledgecelebrates-surpassing-100-signatories.

"Amazon's economic impact in the U.S." About Amazon. Last modified November 9, 2020. https://www.aboutamazon.com/news/job-creation-andinvestment/amazons-economic-impact-in-the-u-s.

David, N., and A. A. Opeyemi. "(PDF) Solar power system: A viable renewable energy source for Nigeria." ResearchGate. Last modified September 30, 2013.

https://www.researchgate.net/publication/257352252_Solar_Power_Syste m_A_Viable_Renewable_Energy_Source_For_Nigeria.

Department of Energy United States of America. "Renewable Energy: An Overview." National Renewable Energy Laboratory (NREL) NREL. Accessed May 10, 2021. https://www.nrel.gov/docs/fy01osti/27955.pdf.

Peischel, Will, and Mother Jones. "90 Percent of U.S. Could Be Powered by 
Renewables by 2035." Yale E360. Last modified June 12, 2020. https://e360.yale.edu/digest/90-percent-of-us-could-be-power-byrenewables-by-2035.

Peltz, James F. "Jeff Bezos Expanded Amazon's Climate Change Pledge. His Workers Want More." Los Angeles Times. Last modified September 21, 2019. https://www.latimes.com/business/story/2019-09-19/amazonclimate-change.

Praetorius, Rachel. "Introducing Our Most Sustainable Devices Ever." About Amazon. Last modified October 30, 2020. https://www.aboutamazon.com/news/devices/introducing-our-mostsustainable-devices-ever.

Silverstein, Ken. "Amazon Tops The 2020 List Of Corporate Renewable Energy Buyers." Forbes. Last modified January 27, 2021. https://www.forbes.com/sites/kensilverstein/2021/01/27/amazon-tops-the2020-list-of-corporate-renewable-energy-buyers/?sh=e45f3e0776d5. 